\title{
Seismic performance of building reinforced with CFRP bars
}

\author{
Suriyati $^{1}$, Ridwan ${ }^{1, *}$, Zulfikar Djauhari $^{1}$, and Iskandar Romey Sitompul ${ }^{1}$ \\ ${ }^{1}$ Department of Civil Engineering, Universitas Riau, Pekanbaru, Indonesia
}

\begin{abstract}
Over the past two decades, laboratory tests have suggested that fibre reinforced polymer (FRP) bars can replace steel bars as internal reinforcement in concrete structures, especially those are subjected to aggressive environments. FRP bars has potential for replacing steel bars as these material are corrosion-resistant and have high tensile strength, make it suitable for use as structural reinforcement. Unfortunately, the application of FRP for reinforcing structures in Indonesia is dubious. This paper aims to study the behaviour of reinforced concrete (RC) building reinforced with Carbon FRP (CFRP) and steel bars. The observed building was designed for Pekanbaru, according to SNI 2847:2013 for design of structural RC with steel bars reinforcement and the ACI 440.1R-15 for design and construction of structural RC with FRP bars. Two reinforcedconcrete moment resisting frames, extracted from 6 storey heights building with rectangular floor plan, were designed for the city of Pekanbaru. The building had the typical storey height of $3.6 \mathrm{~m}$ except for the first floor where the column length was $4.0 \mathrm{~m}$. Two frames were investigated, including the frame without (Frame A) and with shear wall (Frame B). Pushover analysis was conducted to establish the design force and the design deformation demands. The results show that the amount of bar areas needed for reinforcing the building with CFRP bars was significantly reduced. Moreover, the maximum forced demand attained for the building reinforced with CFRP bars were enhanced by about 1.9 times compared to that of reinforced with steel bars.
\end{abstract}

\section{Introduction}

Until a few decades ago, the use of steel bars as internal reinforcement is a common practice to RC structures. Steel bars provide a high strength capacity to resist tensile stress to encounter the nature of the concrete material that is strong in compression but weak in tension. On the other hand, the existence of chlorides (sources from concrete ingredients or penetration of chloride from surrounding environment) and $\mathrm{CO}_{2}$ (sources from concrete carbonation or acidic gases penetrated into concrete) can trigger corrosion on steel bars. Reinforcement bars corrosion lasts at a steady state, and it initiates spalling of concrete cover. As a result, the concrete will deteriorate and lead to the loss of stability of reinforced concrete (RC) structures [1]. Also, the economic impact induced by corrosion on the

\footnotetext{
* Corresponding author: ridwan@eng.unri.ac.id
} 
reconstruction of the affected highway bridge was devastating. Annually, total cost spent to carry out maintenance on the deficient bridge structures in the US was USD 5.2 billion [2].

Several attempts have been developed to overcome the corrosion effect on the reinforcement bars, e.g., the application non-corrosive material to cover reinforcement steel bars, the use of galvanized or stainless steel bars as well as high-performance concrete. Nonetheless, these methods did not eliminate corrosion problem on the bridge structures effectively. Moreover, the rehabilitation costs were doubled comparing to the price for the new structure with alternative construction method [3].

The use of fiber-reinforced polymer (FRP) reinforcement bars became a favorable solution as an alternative to steel bars since it has advantages such as high strength-toweight ratio and corrosion resistant. FRP composites constitute three essential materials: fibers, polymers as well as additives. Additives (e.g., plasticizers, impact modifiers, heat stabilizers, antioxidants, and flame-retardants) were added to enhance the properties of FRPs [4]. On the other hand, the mechanical properties of FRP have a linear characteristics until its failure. The use of such linear elastic material will raise concern the performance of $\mathrm{RC}$ structures since the dissipation of energy is gained from the plastic behavior of the material. However, experimental research [5] revealed that beam-column connection assemblage with Glass FRP as internal reinforcement dissipated 20\% more cumulative energy than that of with the reinforcement steel bars. Moreover, the use of Carbon FRP as internal joint shear reinforcement enhanced the shear strength of the joint by about $40 \%$ comparing to that of with the steel reinforcement bars [6].

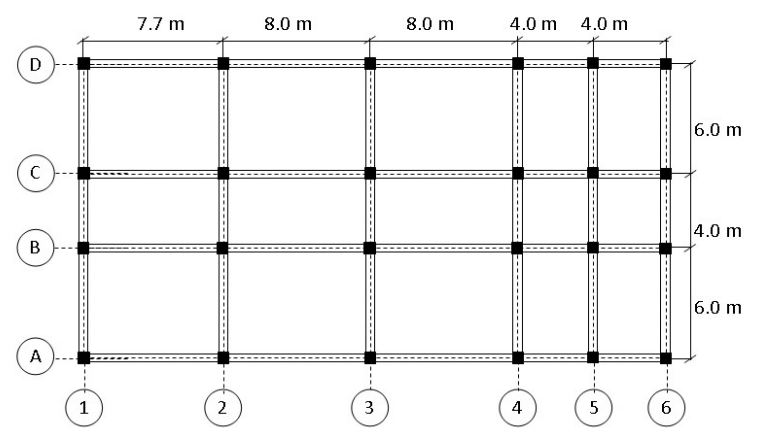

(a)

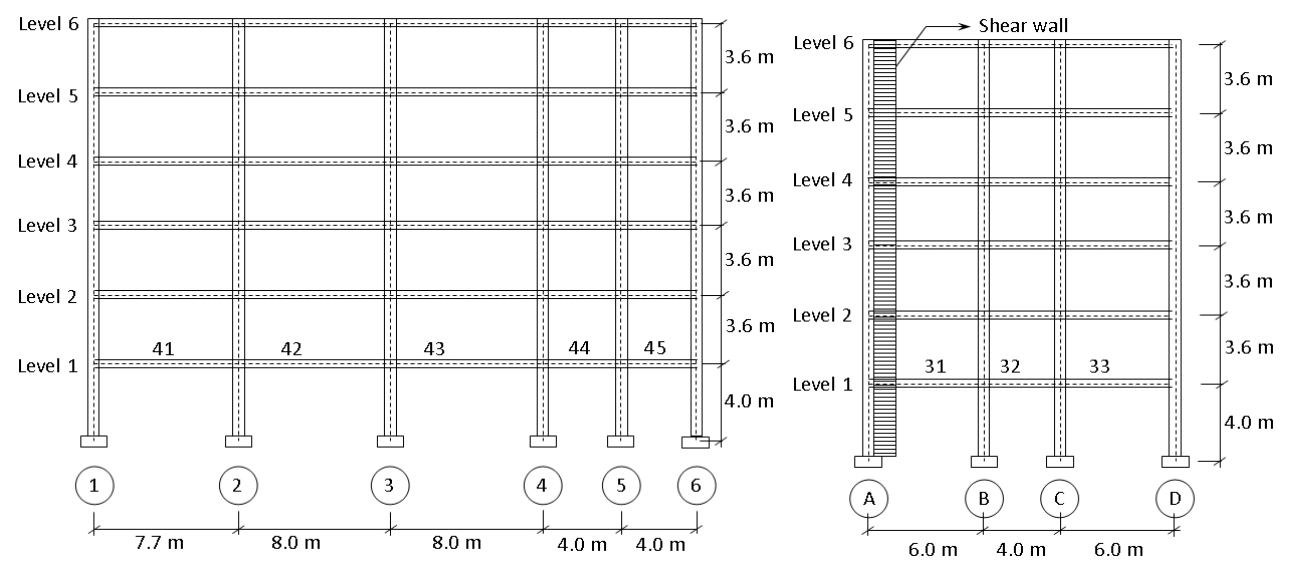

(b)

(c)

Fig. 1. Geometric details of the 6-storey building analysed in this study: (a) Plan view, (b) Elevation view in the long direction-Frame A, (c) Elevation view in the short direction-Frame B. 


\section{Design of building}

Two reinforced concrete moment resisting frames, extracted from 6 story heights building with the rectangular floor plan, was designed for the city of Pekanbaru. The building had the same story height of $3.6 \mathrm{~m}$ except for the first floor where the column length was $4.0 \mathrm{~m}$. The two frames included the frame without (Frame A) and with the shear wall (Frame B) are considered in this study. The floor plan and elevation view of the 6-story building is depicted in Fig. 1.

The existing building was designed according to the SNI 2847:2013 for the design of $\mathrm{RC}$ buildings with steel reinforcement bars. The dead and live designed loads were selected to be $4.2 \mathrm{kN} / \mathrm{m}^{2}$ and $2.87 \mathrm{kN} / \mathrm{m}^{2}$, respectively. The normal concrete cylinder strength of 20.75 $\mathrm{MPa}$ was employed throughout the design while the yield strength and elastic modulus of longitudinal and shear reinforcement bars were $400 \mathrm{MPa}$ and $200 \mathrm{GPa}$, and 240 $\mathrm{MPa}$ and $200 \mathrm{GPa}$ respectively.

Table 1. Reinforcement details for beams on Frame A.

\begin{tabular}{|c|c|c|c|c|c|}
\hline \multirow{2}{*}{ Beam ID } & \multirow{2}{*}{ Location } & \multicolumn{2}{|c|}{ Steel bars } & \multicolumn{2}{c|}{ CFRP bars } \\
\cline { 3 - 6 } & & Bars & $\mathbf{M u}_{\mathbf{u}} / \varnothing \mathbf{M}_{\mathbf{n}}$ & Bars & $\mathbf{M}_{\mathbf{u}} / \varnothing \mathbf{M}_{\mathbf{n}}$ \\
\hline \multirow{3}{*}{41} & Support & $4 \mathrm{D} 19$ & 1.25 & $3 \mathrm{D} 19$ & 1.75 \\
\cline { 2 - 6 } & Midspan & $4 \mathrm{D} 19$ & 1.54 & $3 \mathrm{D} 19$ & 2.16 \\
\hline \multirow{2}{*}{42} & Support & $4 \mathrm{D} 19$ & 1.17 & $3 \mathrm{D} 19$ & 1.63 \\
\cline { 2 - 6 } & Midspan & $4 \mathrm{D} 19$ & 1.58 & $3 \mathrm{D} 19$ & 2.21 \\
\hline \multirow{3}{*}{43} & Support & $4 \mathrm{D} 19$ & 1.13 & $3 \mathrm{D} 19$ & 1.59 \\
\cline { 2 - 6 } & Midspan & $4 \mathrm{D} 19$ & 1.49 & $3 \mathrm{D} 19$ & 2.08 \\
\hline \multirow{2}{*}{44} & Support & $4 \mathrm{D} 19$ & 5.08 & 3D19 & 7.09 \\
\hline \multirow{3}{*}{45} & Support & $4 \mathrm{D} 19$ & 11.24 & 3D19 & 15.63 \\
\cline { 2 - 6 } & Midspan & $4 \mathrm{D} 19$ & 16.39 & 3D19 & 22.73 \\
\hline
\end{tabular}

Table 2. Reinforcement details for beams on Frame B.

\begin{tabular}{|c|c|c|c|c|c|}
\hline \multirow{2}{*}{ Beam ID } & \multirow{2}{*}{ Location } & \multicolumn{2}{|c|}{ Steel bars } & \multicolumn{2}{c|}{ CFRP bars } \\
\cline { 3 - 6 } & & Bars & $\mathbf{M}_{\mathbf{u}} / \varnothing \mathbf{M}_{\mathbf{n}}$ & Bars & $\mathbf{M}_{\mathbf{u}} / \varnothing \mathbf{M}_{\mathbf{n}}$ \\
\hline 31 & Support & $3 \mathrm{D} 19$ & 1.85 & $2 \mathrm{D} 19$ & 3.06 \\
\hline 32 & Support & $3 \mathrm{D} 19$ & 1.19 & $2 \mathrm{D} 19$ & 1.98 \\
\hline 33 & Support & $3 \mathrm{D} 19$ & 1.31 & $2 \mathrm{D} 19$ & 1.48 \\
\hline
\end{tabular}

The same frames were then redesigned following the requirements of ACI 440.1R-15 for design and construction of structural RC with FRP bars. In this study, Carbon FRP (CFRP) bars were used as internal reinforcement with a nominal diameter of $19 \mathrm{~mm}$ (for 
longitudinal bars) and $10 \mathrm{~mm}$ (for shear reinforcement). The tensile strength and elastic modulus of the CFRP bars were $2070 \mathrm{MPa}$ and $152 \mathrm{GPa}$, respectively. The sample of reinforcement details for some beams on respective frames are listed in Table 1 and 2.

Pushover analysis was conducted on selected frames using finite element software and the results gained for the two frames are compared. To account the nonlinearity characteristic of plastic hinges for each element, performance levels, such as immediate occupancy (IO), life safety (LS) and collapse prevention (CP) are assigned to the respective moment-rotation curves during pushover analysis.

\section{Seismic response of reinforced concrete frames}

\subsection{Load displacement behavior}

Fig. 2 depicts the comparison of the load-displacement relationship of the Frame A reinforced with CFRP and steel reinforcement bars. For both types of bars, stiffness degradation was not seen until the frame reach the displacement of $10.6 \mathrm{~mm}$. Stiffness degradation for frame reinforced with steel bars started to increase gradually from the displacement of $25.0 \mathrm{~mm}$ to $86.7 \mathrm{~mm}$. This frame reached the maximum loading capacity $(578.6 \mathrm{kN})$ at the displacement of $510.1 \mathrm{~mm}$. On the other hand, stiffness degradation for frame reinforced with CFRP bars started at the displacement of $13.5 \mathrm{~mm}$. From this point, the stiffness degradation began to increase gradually until it reached the displacement of $230.5 \mathrm{~mm}$. The maximum load attained for the frame reinforced with CFRP bars was $1129.6 \mathrm{kN}$ at the displacement of $481.2 \mathrm{~mm}$. It can be seen that the maximum load achieved for Frame reinforced with CFRP bars was 1.9 times more than that of with steel bars.

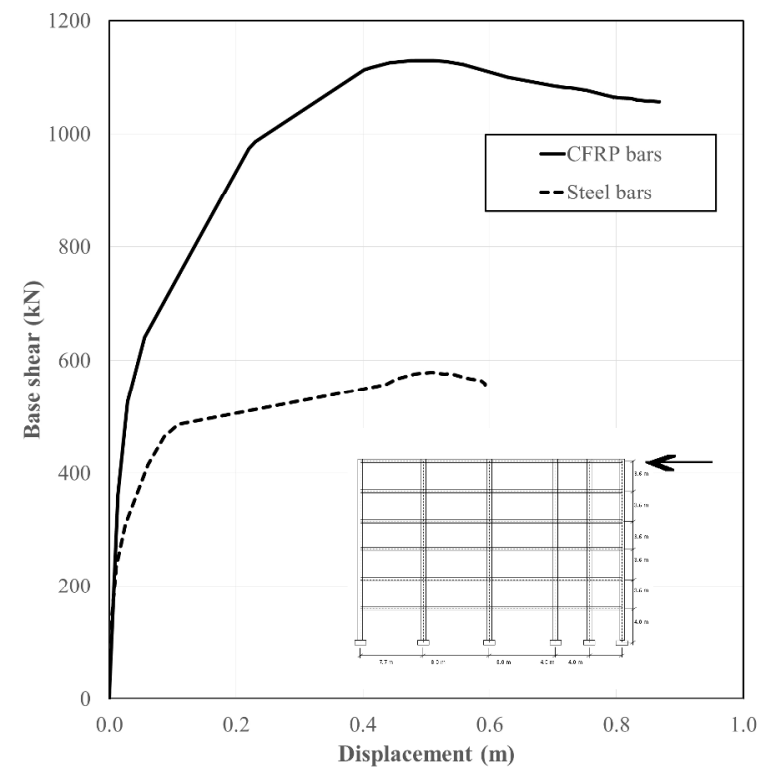

Fig. 2. Load-displacement relationship for Frame A.

The comparison of the load-displacement relationship of the Frame B reinforced with CFRP and steel bars can be seen in Fig. 3. In general, the stiffness for frame reinforced with steel bars was lesser compared to that of reinforced with CFRP bars. The stiffness degradation for frame reinforced with steel bars started at the displacement of $7.0 \mathrm{~mm}$. from 
this point, stiffness degradation increased gradually and the analysis stop due to the model instability. Hence, the maximum loading capacity for this analysis could not be concluded. Comparing to the steel reinforcing bars, the frame reinforced with CFRP bars showed a promising result. Load-displacement relationship showed that this frame had an initial linear response until the displacement of $85.2 \mathrm{~mm}$ at the load of $1936.8 \mathrm{kN}$. Further loading applied to the frame, and the load response increased nonlinearly until the maximum load reached $(2972.2 \mathrm{kN})$. From this point, both the loading capacity and the stiffness decreased gradually.

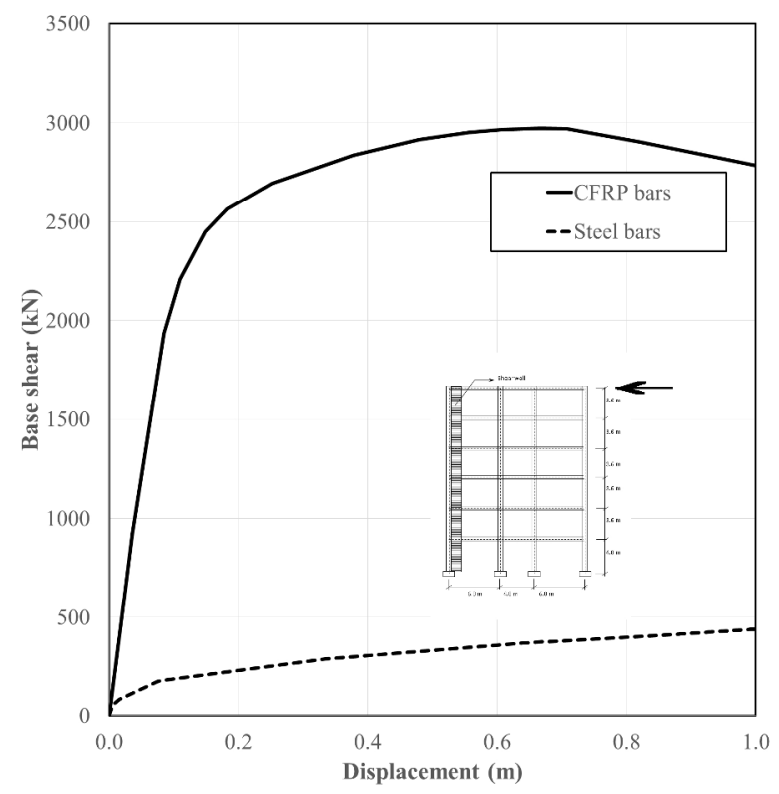

Fig. 3. Load-displacement relationship for Frame B.

\subsection{Displacement ductility}

The displacement ductility $\mu$ is determined by dividing ultimate displacement $\left(\Delta_{\mathrm{u}}\right)$ with yield displacement $\left(\Delta_{\mathrm{y}}\right)$. Ultimate displacement is considered as the displacement at the loading decreases as many as $20 \%$ from the peak load while yield displacement is measured according to reduced stiffness equivalent elasto-plastic yield [7]. In this case, the first yield point is indicated as the displacement at the time load reaches $75 \%$ of the ultimate load, and the yield displacement is obtained by extrapolating the first yield point to a point where the specimen reaches ultimate load.

Displacement ductility measurement according to the theory proposed by Park [7] is shown in Fig. 4. Displacement ductility for the Frame A reinforced with steel bars, Frame A reinforced with CFRP bars, and Frame B reinforced with CFRP bars were, 6.3, 4.1 and 6.2 , respectively. For the case of Frame A, it can be shown that the use of non-ductile material like FRP bars as internal reinforcement on the RC structure did not turn the frame to be a brittle one. Moreover, the combination of the existence of shear wall and the use of CFRP bars (on the case of Frame B) could increase maximum load capacity and at the same time. 


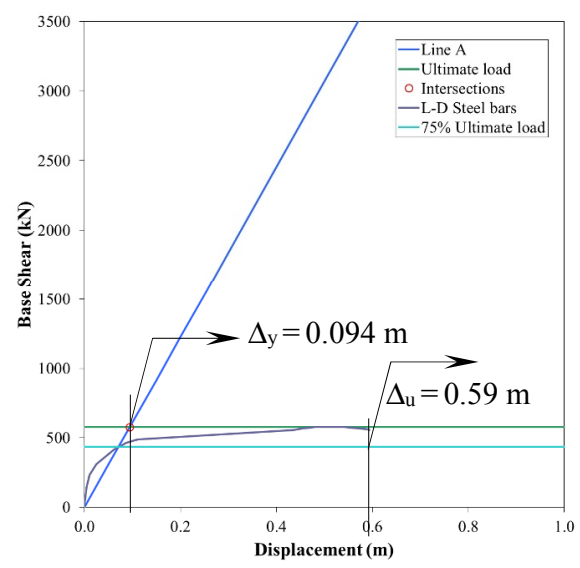

(a)

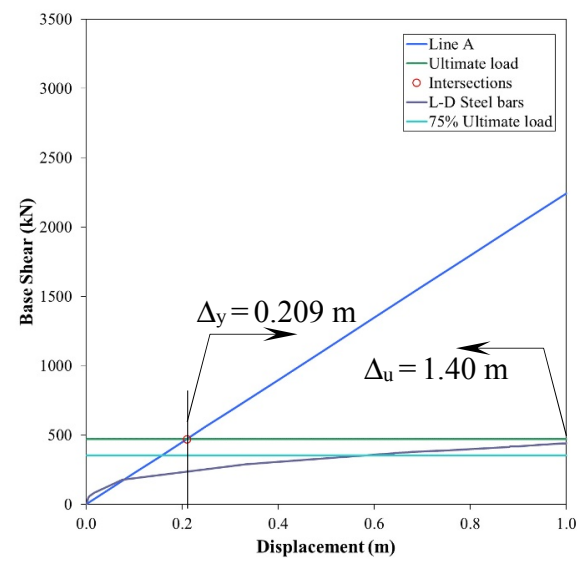

(c)

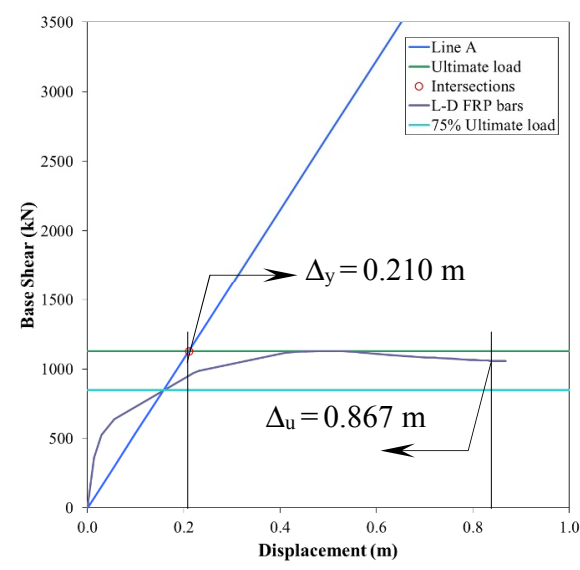

(b)

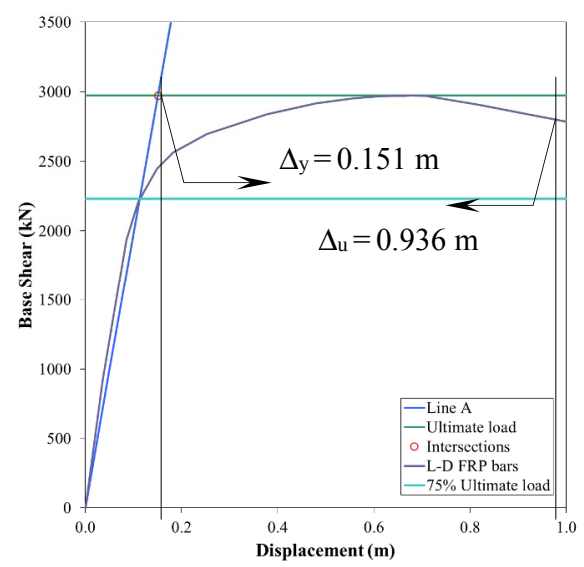

(d)

Fig. 4. Displacement ductility measurement on: (a) Frame A reinforced with steel bars, (b) Frame A reinforced with CFRP bars and, (c) Frame B reinforced with steel bars, (d) Frame B reinforced with FRP bars.

\subsection{Formation of plastic hinges}

Ductility of the structure is a central role design parameter as it represents the ability of the structure to dissipate energy through a post-elastic deformation phase. At this point, the concrete and reinforcement bars will fail in tension or compression at the same time when the plastic hinges are formed. Seismic design philosophy also governs that the formation of plastic hinges on beams is favorable than that of on columns. Fig. 5 and Fig. 6 shows the formation of plastic hinges on Frame A and Frame B, respectively during the pushover analysis. Both pictures show that, under lateral loading, the plastic hinges were formed on beams followed by the formation of hinges on columns. It ensured that tensile failure existed on the elements of the structure. This evidence was supported from the results of the displacement ductility on the previous section. 


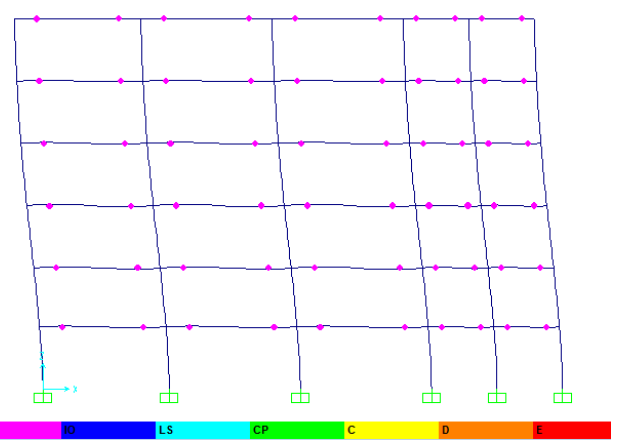

(a)

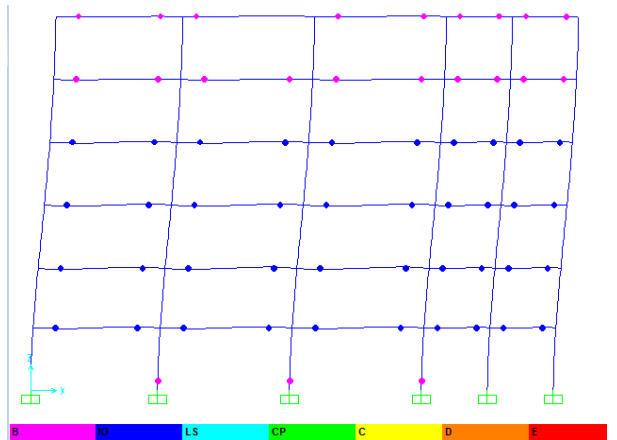

(b)

Fig. 5. The formation of plastic hinges on Frame A (a) reinforced-steel bars, (b) reinforced-FRP bars.

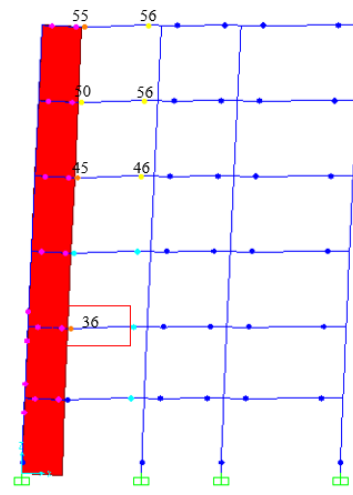

(a)

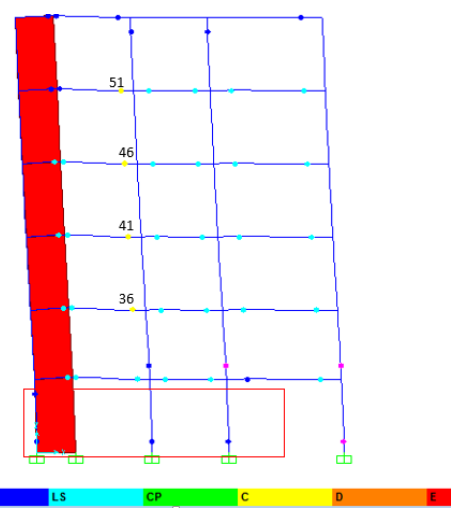

(b)

Fig. 6. The formation of plastic hinges on Frame B (a) reinforced-steel bars, (b) reinforced-FRP bars.

\section{Conclusions}

This paper explores the possibility the use of CFRP bars as internal reinforcement on RC frame structures. Pushover analysis results demonstrate the performance of moment resisting frame reinforced with CFRP bars under lateral loading. Based on the results, the main findings of this study are as follows. The use of CFRP bars on RC structures can increase maximum loading capacity. For the case of Frame A, the maximum load of the frame with CFRP bars were 1.9 times higher than to that of reinforced with the steel bars. The application of CFRP bars on RC structures did not change the frame behaviour to be a brittle one. For the case of Frame A, the ductility of structure with CFRP bars $(\mu=4.1)$ was comparable to the ductility of the structure with steel bars $(\mu=6.3)$.

The authors wish to express their appreciation for the financial support provided by DIPA Universitas Riau under the Grant No. 728/UN.19.5.1.3/PP/2018. The support from the Structural Laboratory Faculty of Engineering Universitas Riau for providing SAP2000 is also acknowledged.

\section{References}

1. S. Ahmad, Cem. Con. Comp. 25 (2003)

2. Y.P. Virmani, G.G. Clemena, Corrosion Protection-Concrete Bridges (Federal Highway Administration, Virginia, 1998) 
3. M. Yunovich, N.G. Thompson, Concrete International 25 ( 2003)

4. H.V.S Gangarao, N. Taly, P.V. Vijay, Reinforced concrete design with FRP composites (CRC Press, Boca Raton, 2007)

5. M. Mady, A. El-Ragaby, E. El-Salakawy, J. Comp. Con. 15 (2011)

6. R. Rahman, S. Dirar, Y. Jemaa, M. Theofanous, M. Elshafie J. Comp. Con. (2018)

7. R. Park, Bull. of the New Zealand National Soc. for Earthq. Eng (1989) 